\title{
Frequency of Direct Oral Anticoagulants Usage in Acute Pulmonary Thromboembolism Treatment in Turkey (TUPEDO)
}

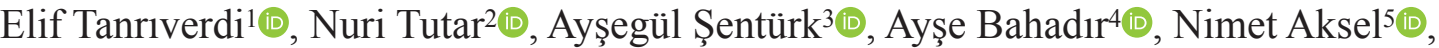

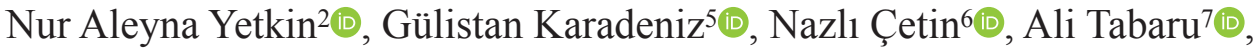
Binnaz Zeynep Yıldırım¹, Hatice Selimoğlu Şen ${ }^{8}{ }^{\circledR}$, Neslihan Özçelik ${ }^{9}$, Emine Özsar110®,

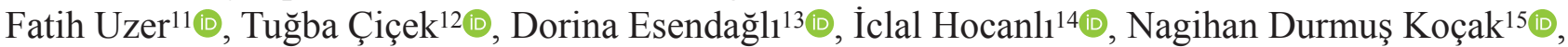

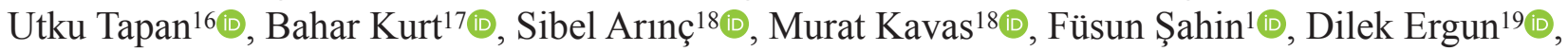

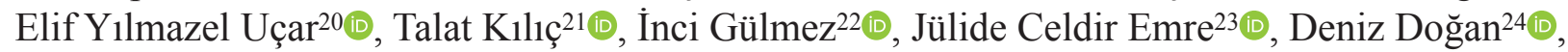

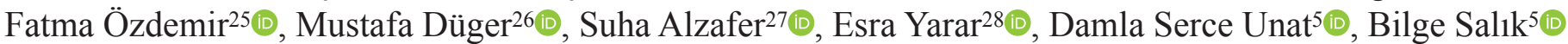

\footnotetext{
${ }^{1}$ Clinic of Chest Diseases, University of Health Sciences Turkey, Yedikule Pulmonary Diseases and Thoracic Surgery Education and Research Hospital, İstanbul, Turkey

${ }^{2}$ Department of Pulmonary, Faculty of Medicine, Erciyes University, Kayseri, Turkey

${ }^{3}$ Clinic of Pulmonary Diseases, University of Health Sciences Turkey, Atatürk Pulmonary Diseases and Thoracic Surgery Education and Research Hospital, Erzurum, Turkey

${ }^{4}$ Clinic of Chest Diseases, Başakşehir Çam and Sakura City Hospital, İstanbul, Turkey

${ }^{5}$ Clinic of Chest Diseases, University of Health Sciences Turkey, Dr. Suat Seren Chest Diseases and Surgery Training and Research Hospital, İzmir, Turkey

${ }^{6}$ Deparment of Pulmonology, Faculty of Medicine, Pamukkale University, Denizli, Turkey

${ }^{7}$ Clinic of Pulmonology, Söke City Hospital, Aydın, Turkey

${ }^{8}$ Department of Chest Disease, Faculty of Medicine, Dicle University, Diyarbakır, Turkey

${ }^{9}$ Department of Pulmonology, Faculty of Medicine, Recep Tayyip Erdoğan University, Rize, Turkey

${ }^{10}$ Department of Pulmonology, Faculty of Medicine, Abant İzzet Baysal University, Bolu, Turkey

${ }^{11}$ Clinic of Respiratory Disease, Kastamonu State Hospital, Kastamonu, Turkey

${ }^{12}$ Clinic of Chest Disease, Konya Numune Hospital, Konya, Turkey

${ }^{13}$ Department of Pulmonology, Faculty of Medicine, Başkent University, Ankara, Turkey

${ }^{14}$ Department of Pulmonology, Faculty of Medicine, Harran University, Şanlıurfa, Turkey

${ }^{15}$ Clinic of Chest Disease, Sancaktepe Şehit Prof. Dr. İlhan Varank Research and Training Hospital, İstanbul, Turkey

${ }^{16}$ Department of Chest Diseases, Faculty of Medicine, Muğla Sitkı Koçman University, Muğla, Turkey

${ }^{17}$ Clinic of Chest Disease, Dışkapı Education and Research Hospital, Ankara, Turkey

${ }^{18}$ Clinic of Chest Diseases, University of Health Sciences Turkey, Süreyyapaşa Chest Diseases and Thoracic Surgery Training and Research Hospital, İstanbul, Turkey

${ }^{19}$ Department of Chest Disease, Faculty of Medicine, Selçuk University, Konya, Turkey

${ }^{20}$ Department of Chest Disease, Faculty of Medicine, Atatürk University, Erzurum, Turkey

${ }^{21}$ Department of Chest Disease, Faculty of Medicine, İnönü University, Malatya, Turkey

${ }^{22}$ Department of Chest Disease, Faculty of Medicine, Erciyes University, Kayseri, Turkey

${ }^{23}$ Clinic of Pulmonology, Turgutlu State Hospital, Manisa, Turkey

${ }^{24}$ University of Health Sciences Turkey, Gülhane Training and Research Hospital, Ankara, Turkey
}

\footnotetext{
Corresponding author: Elif Tanrıverdi, Clinic of Chest Diseases, Yedikule Pulmonary Diseases and Thoracic Surgery Education and Research Hospital, İstanbul, Turkey e-mail: dr.elif06@gmail.com

Received: October 5, 2021 Accepted: December 23, 2021 Available Online Date: March, 14, 2022 • DOI: 10.4274/balkanmedj.galenos.2021.2021-10-19

Available at www.balkanmedicaljournal.org

ORCID iDs of the authors: E.T.- 0000-0002-6049-7229; N.T.- 0000-0003-3097-4896; A.Ş. 0000-0002-1072-0592; A.B.- 000-0002-7006-5550;

N.A.- 0000-0001-8725-3323; N.A.Y.- 0000-0001-5974-9129; G.K.- 0000-0002-1994-6723; N.Ç.- 0000-0002-9077-0580; A.T.- 0000-0002-0072-7221;

B.Z.Y.- 0000-0002-2228-8215; H.S.Ş.- 0000-0002-2597-6646; N.Ö.- 0000-0002-4672-6179 21; E.Ö.- 0000-0001-5842-7849; F.U.- 0000-0001-9318-0458;

T.C.- 0000-0002-1049-6877; D.E.- 0000-0002-6619-2952; İ.H. -0000-0003-3283-9639; N.D.K.- 0000-0002-2808-9233; U.T.- 0000-0002-2808-9233;

B.K.- 0000-0002-3495-2339; S.A.- 0000-0002-2443-2639; M.K.- 0000-0001-9025-6605; F.S.- 0000-0002-8415-2524; D.E.- 0000-0002-9890-2250;

E.Y.U.- 0000-0001-8284-1038; T.K.- 0000-0001-8125-9062; I.G.- 0000-0002-4476-2213; J.C.E.- 0000-0003-3036-9776; D.D.- 0000-0003-2596-3113;

F.Ö.- 0000-0001-8487-4511; M.D.- 0000-0002-4091-6465; S.A.- 0000-0001-7474-3171; E.Y.- 0000-0002-9593-4441; D.S.U.- 0000-0003-4743-5469;

B.S.- 0000-0002-8999-0287.

Cite this article as:

Tanrıverdi E, Tutar N, Şentürk A, et al. Frequency of Direct Oral Anticoagulants Usage in Acute Pulmonary Thromboembolism Treatment in Turkey (TUPEDO). Balkan Med J.; 2022; 39(2):148-52.

Copyright@Author(s) - Available online at http://balkanmedicaljournal.org/
} 


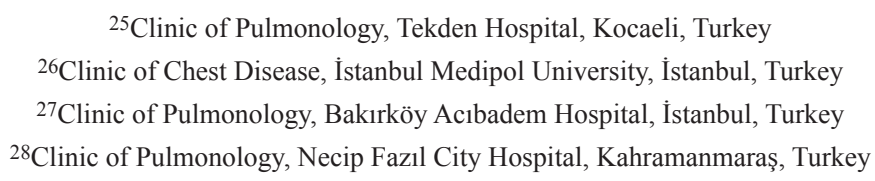

Background: Direct oral anticoagulants (DOACs) have been used in acute pulmonary thromboembolism as an alternative to warfarin due to drug interactions, narrow therapeutic range, and necessary close International Normalized Ratio (INR) monitoring. Phase 3 study results have reported that these drugs are at least as effective as warfarin and beneficial in terms of bleeding; however, studies that present up-to-date life data are necessary.

Aims: To evaluate the frequency of using DOACs, which are prescribed with a limited number of indications in our country, and real-life data results.

Study Design: Cross-sectional study

Methods: This cross-sectional survey collected the clinical data (history, current treatment, treatment duration, etc.) of patients with pulmonary thromboembolism and who applied to the physician for follow-up between October 15, 2019, and March 15, 2020. The researchers kept the patient records sequentially.

Results: Data from 836 patients with acute pulmonary thromboembolism from 25 centers were collected, and DOAC was used in $320(38.5 \%)$ of them. The most preferred DOAC was rivaroxaban $(\mathrm{n}=294,91.9 \%)$. DOAC was mostly preferred because it could not provide an effective INR level with warfarin $(n=133$, $41.6 \%)$. Bleeding was observed in $13(4 \%)$ patients.

Conclusion: The use of direct oral anticoagulants is becoming almost as widespread as conventional therapy. Real-life data results are important for their contribution to clinical practice.

\section{INTRODUCTION}

Warfarin is used in pulmonary thromboembolism (PTE) treatment and has a narrow therapeutic index, drug and food interactions require routine monitoring and dose adjustment. Thus, warfarin treatment follow-up is difficult; therefore, direct oral anticoagulants (DOAC) are increasingly used due to minimum monitoring, low drug interactions, and wide therapeutic ranges. ${ }^{1}$ Three large phase studies evaluated the effectiveness of DOACs and revealed that these drugs are at least as effective as warfarin in terms of antithrombotic efficacy and are associated with less major and/or minor bleeding events..$^{2-8}$ The European Society of Cardiology and the European Respiratory Society guideline have recommended DOACs as the first treatment option for acute pulmonary embolism in eligible patients. ${ }^{9}$ The following terms of use are stated in the Communiqué on Health Practices in our country:

1. In cases where the target International Normalized Ratio (INR) value cannot be kept between 2 and 3 with warfarin in at least three of the last five measurements made at least 1 week apart after using warfarin for at least 2 months

2. Regardless of the condition of warfarin use, DOAC can be used in patients with recurrent idiopathic PTE, active cancer, homozygous thrombophilia with previous venous thromboembolism, or are immobile (provided that the reason is stated in the report). ${ }^{10} \mathrm{The}$ advantages of DOACs, such as simplified acute and long-term therapies in PTE treatment, improving patient outcomes, and increasing patient compliance, make them an attractive alternative to traditional therapy. However, the use of DOACs in patients with PTE having high-risk features or cancer and frail populations remains controversial. ${ }^{11}$ Thus, our study aimed to evaluate the frequency of DOAC usage in our country, the preferred patient groups, and the reasons for use.

\section{MATERIALS AND METHODS}

The prospective cross-sectional survey study is based on the analysis of the national data on patients with PTE. The study was approved by the Ethical Committee of İstanbul Training and Research Hospital (2019/2004). Afterward, questionnaire forms were sent to the study centers. The clinical data (history, current treatment, treatment duration, etc.) of patients with PTE and who applied to the physician for follow-up between October 15, 2019, and March 15, 2020, were recorded by the centers. All patients aged 18 years or over who received anticoagulant therapy with PTE confirmed by computed tomography pulmonary angiography (CT-PA) or ventilation-perfusion (V/Q) scintigraphy were included in the study. Researchers were asked to ensure that patient records were consecutive. Patients who were just diagnosed and whose treatment was started for the first time were excluded from the study. Patients, who were already taking anticoagulant therapy, were included in the study at the first admission during the study period and were excluded from the study at the next follow-up visits.

\section{Statistical Analysis}

Descriptive statistics, measures of central distribution and tendency, frequencies, and percentages were used to present the data analysis. The Statistical Package for Social Sciences version 22.0 for Windows software (IBM SPSS Statistics Data Editor) was used for data analyses. Descriptive data were represented as the number of participants and frequency. Continuous variables were represented as mean and standard deviation, and the Shapiro-Wilk test was used to determine the normality distribution of variables.

Based on the novel oral anticoagulants preference rates in previous studies, the required sample size was calculated as 797 for the study to have a power of 0.80 and a $1 \%$ margin of error. Upon 
adding $5 \%$ to account for the probable drop, a total sample size of 837 resulted.

\section{RESULTS}

Thirty-three researchers, all of whom were pulmonologists, participated in our study from 25 centers. They were working in 11 State Universities, 4 Training and Research Hospitals, 4 Chest Diseases Branch Hospitals, 4 State Hospitals, and 3 Private Universities. Data of 836 patients with acute PTE were collected. Most patient data were recorded from tertiary branch hospitals. Distribution rates of patients according to centers are given in Figure 1.

The mean age of patients was $61.6 \pm 15.8$ years, of whom 438 (52.4\%) were males. Low molecular weight heparin (LMWH) was sed in $226(27 \%)$ patients, warfarin in $289(34.5 \%)$, and DOAC in $320(38.5 \%)$. Only $1(0.1 \%)$ patient had a vena cava filter. Among 320 patients using DOAC, the most preferred was rivaroxaban $(\mathrm{n}=294,91.9 \%)$, whereas 18 patients $(5.6 \%)$ with apixaban, $5(1.6 \%)$ with dabigatran, and $3(0.9 \%)$ with edoxaban. Of the patients who used DOAC, 133 (41.6\%) did not achieve the targeted INR level with warfarin treatment, 101 (31.6\%) had logistical (rural life, etc.) problems in warfarin monitoring, 74 $(23.1 \%)$ had their preference, $62(19.4 \%)$ with immobilization, $62(19.4 \%)$ with recurrent embolism, 43 (13.4\%) with a thrombophilic genetic mutation, $30(9.4 \%)$ with cancer, and 31 (9.7\%) with accompanying atrial fibrillation (AF)/arrhythmia (Table 1).Considering the distribution of physicians in starting DOAC treatment, 158 (49.4\%) personally filled out the form, 134 $(41.9 \%)$ by another physician in the same hospital, $10(3.1 \%)$ by another state hospital, $9(2.8 \%)$ by physicians of another training and research hospital, $6(1.9 \%)$ by another university hospital physicians, and $3(0.9 \%)$ by other private hospital physicians (Figure 2).

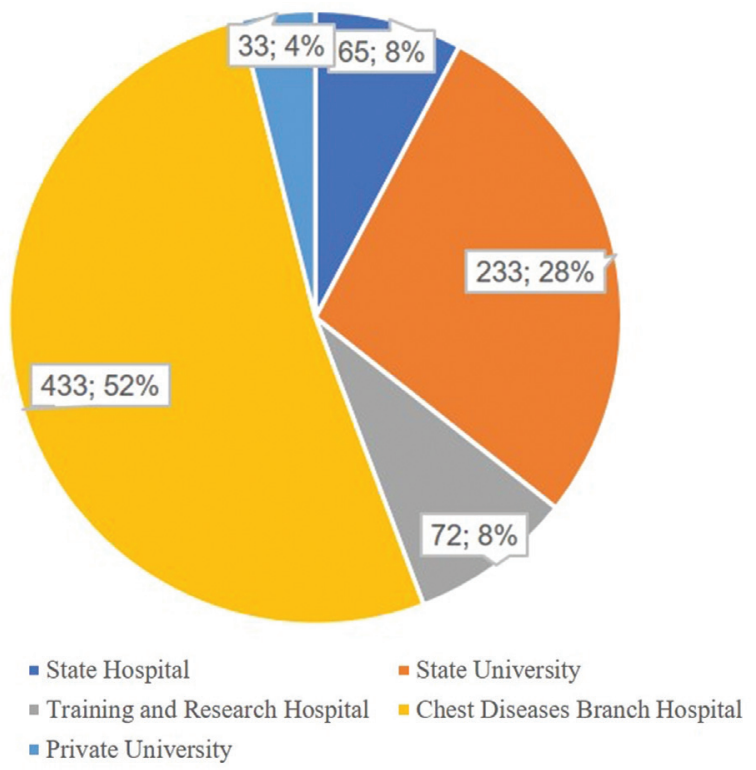

FIG. 1. Distribution rates of patients from centers.
The median duration of DOAC use was 6 months (min: 1 and max: 58). Before DOAC, 244 (76\%) patients had used another anticoagulant (LMWH or warfarin), with the median duration of use of these anticoagulants being 30 days (min: 1 and max: 6205). In $76(24 \%)$ patients, DOAC was initiated at the time of diagnosis. Another antiaggregant drug is used by $30(13.3 \%)$ of 226 patients using LMWH, 29 (10\%) of 289 patients using warfarin, and 27 $(8.5 \%)$ of 320 patients using DOAC.

Considering the frequency of DOAC preference according to the patients' comorbidity, $33(22.6 \%)$ of 146 patients with cancer were using DOAC. The preference for DOAC was higher in patients with hypertension and hyperlipidemia compared to other anticoagulants. The rates of anticoagulants preferred according to comorbidities are presented in Figure 3. The comparison of patients with and without cancer in DOAC treatment duration revealed no statistically significant difference between the two groups (median 6 months [min: 1 and max: 48]; median 6 months [min: 1 and max: 210]; $P=0.565$, respectively). DOAC was used by $41(12.8 \%)$ patients who were 80 years old or older. The most common comorbidity was hypertension $(n=132,41.25 \%)$. No patients were with creatinine clearance of $<30 \mathrm{ml} / \mathrm{min}$, whereas 12

TABLE 1. Reasons for direct oral anticoagulants Usage*

\begin{tabular}{lc}
\hline & $\mathrm{n}(\%)$ \\
\hline Failure to maintain the INR level & $133(41.6)$ \\
Logistical (rural life, etc.) problems in warfarin monitoring & $101(31.6)$ \\
Patient preference & $74(23.1)$ \\
Immobilization & $62(19.4)$ \\
Recurrent embolism & $62(19.4)$ \\
Presence of thrombophilia genetic mutation & $43(13.4)$ \\
Concomitant AF & $31(9.7)$ \\
Cancer & $30(9.4)$ \\
Bleeding under warfarin therapy & $3(0.94)$ \\
$* *$ HiT & $1(0.31)$ \\
\hline$*$ Patients who used direct oral anticoagulants for more than one reason. & \\
$* *$ Heparin-induced thrombocytopenia. & \\
\hline
\end{tabular}

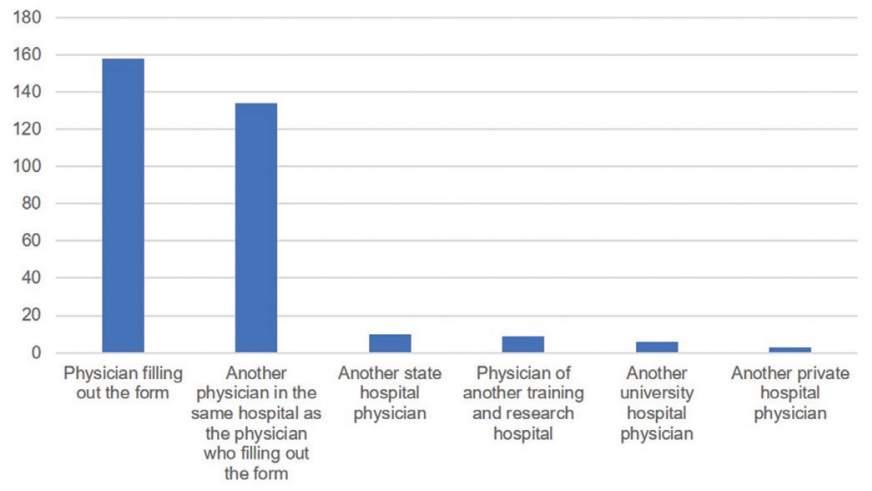

FIG. 2. Distribution of physicians who started direct oral anticoagulants treatment. 
patients have $30-50 \mathrm{ml} / \mathrm{min}(3.7 \%)$. Bleeding was reported in 13 (4\%) of 320 patients using DOAC, of which 8 (2.5\%) were minor and $5(1.5 \%)$ were major bleeding that require urgent admission. No history of accompanying malignancy was found in patients with bleeding, and all patients were younger than 80 years old. No statistically significant difference was found between the ages of patients with and without bleeding $(56.5 \pm 15.7$ and $62.36 \pm 16.3$, respectively, $P=0.21)$. Bleeding was seen in $11(4.5 \%)$ of 244 patients who received bridging treatment, whereas $2(2.6 \%)$ of 76 patients who did not receive bridging treatment $(P=0.469)$.

\section{DISCUSSION}

This study investigated the use of DOACs in patients who received anticoagulant treatment with a proven PTE diagnosis in Turkey and revealed that DOACs were prescribed for treatment in almost half of the patients. DOACs were preferred as a bridging treatment rather than the initial treatment for various reasons, mainly because of the failure to provide the required INR dose with warfarin. In this cross-sectional real-life data, bleeding rates were observed similar to the literature. ${ }^{12-14}$ Studies that showed the effectiveness and safety of DOACs recommended it as the first choice for anticoagulation therapy in the appropriate patient in the European Society of Cardiology (ESC)/European Respiratory Society guideline for PTE management. Reallife data regarding the prescription frequency of DOACs have started to be presented in some countries nowadays. ${ }^{12-14}$ To the best of our knowledge, this is the first study from Turkey that focused on PTE treatment. The evaluation of all patients with PTE in this study revealed that DOACs were prescribed at a rate of $38.5 \%$ for treatment. Studies related to DOAC usage from our country are mostly conducted in patients with AF. The study that examined the Turkey data of the Global Anticoagulant Registry in the Field-AF revealed that the rate of DOAC initiation was $42.5 \%$ in the whole cohort. ${ }^{15}$ The RAMSES study reported a $37 \%$ rate of using DOAC in patients with AF. The results of both studies were similar to ours. The RAMSES study stated that the use of DOACs started to increase compared to previous studies due to the launching of drugs in our country and its

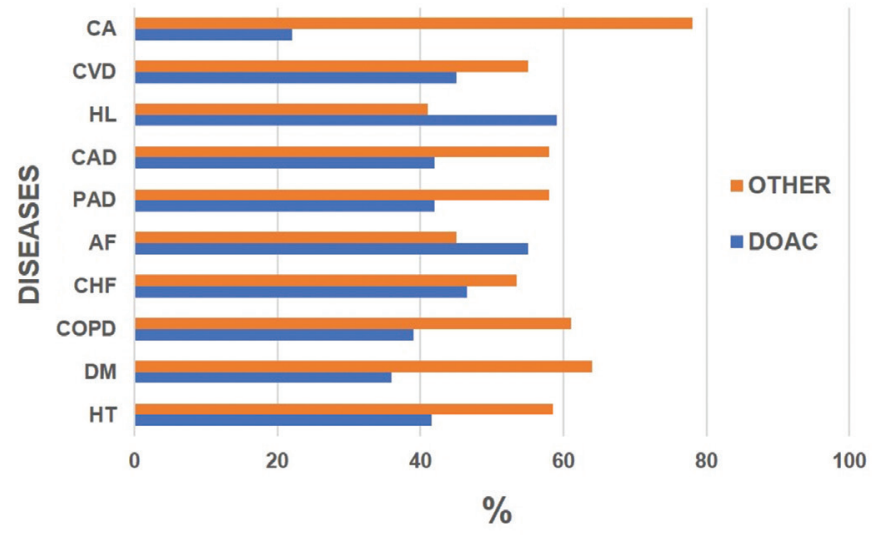

FIG. 3. Preference rates of direct oral anticoagulants according to the presence of comorbidities. recommendation as an alternative treatment for warfarins in the ESC 2012 guideline. The most commonly used DOAC in their study was dabigatran (18\%), followed by rivaroxaban $(15 \%)$ and apixaban (4\%). ${ }^{16}$ Usage rates were in line with the dates when drugs were reimbursed by the Ministry of Health (May 2013 for dabigatran, October 2013 for rivaroxaban, and July 2014 for apixaban) in our country. Dabigatran was reported as the most commonly used DOAC in a study conducted in our country that included all patient groups, including a limited number of patients with PTE.${ }^{17}$ Our study, unlike all these studies, revealed that rivaroxaban was the most preferred DOAC because of its ease of use in a single dose and inexpensive with similar efficacy. Additionally, while other studies were conducted with the participation of cardiologists, this study was conducted by pulmonologists. The differences between the physician groups suggested that in-branch training, correspondence, and webinars may be effective in the choice.

Our study revealed that $76 \%$ of patients were administered bridging therapy after another anticoagulant before DOAC treatment. The study of Jara-Palomares et al. revealed that $71 \%$ of patients had switched to rivaroxaban after previous treatment with heparin or warfarin. ${ }^{13}$ Another study revealed that $52.4 \%$ of patients were using another anticoagulant before changing their treatment to rivaroxaban. This study revealed that the average duration of use of other anticoagulants before rivaroxaban was 28 days and was similar to our study. ${ }^{14}$ Additionally, the most common reasons for switching to rivaroxaban were logistical difficulties for warfarin monitoring, inability to stabilize INR levels, and patient preference. Our study revealed the same reasons for initiating DOAC treatment. ${ }^{14}$ The bleeding rates associated with DOAC in our study were similar to those in these two studies. ${ }^{13,14}$ No relationship was observed between bleeding and patient age, additional antiaggregant use, and cancer history. Studies revealed that the bleeding rates could be affected by bridging therapy. However, in these studies the rates of patients who underwent bridging therapy were high. Unlike these two studies, our study revealed no statistically significant difference in bleeding rates between those with and without bridging therapy. Generally, considering the average age of our patients using DOAC and the use of additional antiaggregant and creatinine clearance values, the low bleeding rates may have been due to careful patient selection in the possibility of bleeding.

Our study has some limitations. The snapshot of the patient characteristics was evaluated since it was a cross-sectional study, thus we could not give information about the course of PTE, such as chronic thromboembolic pulmonary hypertension or embolism under DOAC treatment. Additionally, the focus was on investigating the frequency of DOAC usage and the reasons for their preference, thus patient characteristics that used other anticoagulants were not evaluated in detail. Therefore, sufficient data could not be obtained to compare the characteristics of the two groups.

DOACs are used in PTE treatment in our country with considerable frequency. Bleeding frequency associated with DOAC was consistent with the literature. Bleeding was not observed with 
age, bridging therapy, and the presence of cancer. According to the literature, the low rate of bleeding was mostly associated with the selection of patients with low-risk bleeding and a low rate of antiaggregant usage. Our study draws attention to the increased use of DOAC in our country. This awareness is thought to guide future studies in investigating the effectiveness of these drugs in daily life in preventing embolic complications and comparing them with other anticoagulants.

Ethics Committee Approval: Ethics committee approval was received from the Ethics Committee of Istanbul Education and Research Hospital (date: 27/09/2019, approval number: 2004).

Data Sharing Statement: The data that support the findings of this study are available from the corresponding author upon reasonable request.

Author Contributions: Concept and Design - E.T., N.T.; Supervision - G.K., A.B., A.Ş., N.A., N.D.K.; Data Collection and/or Processing - A.Ş., A.B., N.A., N.A.Y., G.K., N.Ç., A.T., B.Z.Y., H.S.Ş., N.Ö., E.Ö., F.U., T.Ç., D.Esendağl1, İ.H., N.D.K., U.T., B.K., S.A., M.K., F.Ş., D.Ergun, E.Y.U., T.K., İ.G., J.Ç.E., D.D., F.Ö., M.D., S.A., E.Y., D.S.U., B.S.; Analysis and/or Interpretation - E.T., N.T., B.Z.Y.; Literature Search - E.T., N.T., D.D.; Writing - E.T.; Critical Review - N.T., N.D.K.

Conflict of Interest: The authors have no conflict of interest to declare.

Funding: The authors declared that this study has received no financial support.

\section{REFERENCES}

1. Conway SE, Hwang AY, Ponte CD, Gums JG. Laboratory and Clinical Monitoring of Direct Acting Oral Anticoagulants: What Clinicians Need to Know. Pharmacotherapy. 2017;37:236-248. [CrossRef]

2. Einstein Investigators, Bauersachs R, Berkowitz SD, et al. Oral rivaroxaban for symptomatic venous thromboembolism. New Engl J Med. 2010;363:2499-2510. [CrossRef]

3. Einstein-PE Investigators, Buller HR, Prins MH, et al. Oral rivaroxaban for the treatment of symptomatic pulmonary embolism. New Engl J Med. 2012;366:12871297. [CrossRef]

4. Agnelli G, Buller HR, Cohen A, et al. Oral apixaban for the treatment of acute venous thromboembolism. N Engl J Med. 2013;369:799-808. [CrossRef]

5. Schulman S, Kakkar AK, Goldhaber SZ, et al. Treatment of acute venous thromboembolism with dabigatran or warfarin and pooled analysis. Circulation. 2014;129:764-772. [CrossRef]
6. Hokusai VTE Investigators, Buller HR, Decousus H, et al. Edoxaban versus warfarin for the treatment of symptomatic venous thromboembolism. New Engl J Med. 2013;369:1406-1415. [CrossRef]

7. Schulman S, Kearon C, Kakkar AK, et al. Dabigatran versus warfarin in the treatment of acute venous thromboembolism. New Engl J Med. 2009;361:2342-2352. [CrossRef]

8. Prins MH, Lensing AW, Bauersachs R, et al. Oral rivaroxaban versus standard therapy for the treatment of symptomatic venous thromboembolism: a pooled analysis of the EINSTEIN-DVT and PE randomized studies. Thrombosis Journal. 2013;11:21. [CrossRef]

9. Konstantinides SV, Meyer G, Becattini C, et al. The Task Force for the diagnosis and management of acute pulmonary embolism of the European Society of Cardiology (ESC). 2019 ESC Guidelines for the diagnosis and management of acute pulmonary embolism developed in collaboration with the European Respiratory Society (ERS): The Task Force for the diagnosis and management of acute pulmonary embolism of the European Society of Cardiology (ESC). Eur Respir J. 2019;54:1901647. [CrossRef]

10. (24.03.2013 Resmî Gazete Sayıs1: 28597.) [CrossRef]

11. Eldredge JB, Spyropoulos AC. Direct oral anticoagulants in the treatment of pulmonary embolism. Curr Med Res Opin. 2018;34:131-140. [CrossRef]

12. Chopard R, Andarelli JN, Humbert S, et al. Prescription patterns of direct oral anticoagulants in pulmonary embolism: A prospective multicenter French registry. Thromb Res. 2019;174:27-33. [CrossRef]

13. Jara-Palomares L, Sanchez-Oro-Gomez R, Elias-Hernandez T, et al. Rivaroxaban for the treatment of venous thromboembolism. A 'real-life' perspective in 103 patients. Thromb Res. 2014;34:617-621. [CrossRef]

14. Imberti D, Barillari G; eXperience VTE Italian Group. Real-Life Management of Venous Thromboembolism With Rivaroxaban: Results From EXperience VTE, an Italian Epidemiological Survey. Clin Appl Thromb Hemost. 2018;24:241-247. [CrossRef]

15. Sayın B, Okutucu S, Yilmaz MB, et al. Antithrombotic treatment patterns and stroke prevention in patients with atrial fibrillation in TURKEY: inferences from GARFIELD-AF registry. Anatol J Cardiol. 2019;21:272-280. [CrossRef]

16. Başaran O, Beton O, Doğan V, et al. ReAl-life Multicenter Survey Evaluating Stroke prevention strategies in non-valvular atrial fibrillation (RAMSES study). Anatol $J$ Cardiol. 2016;16:734-741. [CrossRef]

17. Altay S, Yıldırımtürk Ö, Çakmak HA, et al. New oral anticoagulants-TURKey (NOAC-TURK): Multicenter cross-sectional study. Anatol J Cardiol. 2017;17:353361. [CrossRef] 